\title{
Analisis Kebutuhan Penyusunan Buku Ajar Tata Bahasa Jerman
}

\author{
Mantasiah R. ${ }^{1}$, Amir $^{2}$, Yusri3 ${ }^{3}$, Muhammad Anwar ${ }^{4}$ \\ Program Studi Pendidikan Bahasa Jerman, Universitas Negeri Makassar 1,3,4 \\ Program Studi Teknologi Pendidikan, Universitas Negeri Makassar ${ }^{2}$ \\ Email:mantasiah@unm.ac.id'
}

\section{E-ISSN : $2579-4574$}

P-ISSN : 2549-7359

\begin{abstract}
Abstrak. Penelitian ini bertujuan untuk menganalisis kebutuhan penyusunan buku ajar tata bahasa Jerman berdasarkan respon mahasiswa. Data ini nantinya akan digunakan sebagai dasar dalam penyusunan buku ajar tata bahasa Jerman. Jenis penelitian yang digunakan adalah kualitatif dengan pendekatan deskriptif kualitatif. Partisipan yang dilibatkan adalah 30 mahasiswa pendidikan bahasa Jerman yang telah memprogramkan mata kuliah tata bahasa Jerman dasar. Teknik pengumpulan data yang digunakan yakni wawancara dan observasi. Hasil penelitian menunjukkan bahwa terdapat 4 aspek yang sebaiknya diperhatikan dalam penyusunan buku ajar tata bahasa diantaranya adalah 1) Komposisi setiap materi harus disesuaikan dengan analisis kebutuhan pembelajar menggunakan analisis kesalahan berbahasa, 2) Penggunaan Analisis Kontrastif untuk Menjelaskan Tata Bahasa Jerman, 3) Bentuk Soal Latihan yang Diberikan harus Bervariasi, 4) Menjelaskan Fenomena Tata Bahasa Jerman dengan Menggunakan Pendekatan Linguistik.
\end{abstract}

Keywords: Analisis Kebutuhan, Bahasa Jerman, Tata Bahasa, Buku Ajar, Linguistik Terapan

\section{https://ojs.unm.ac.id/eralingua}

\section{PENDAHULUAN}

Penelitian yang fokus mengkaji pengembangan bahan ajar bahasa asing telah banyak dilakukan oleh peneliti-peneliti sebelumnya (Koda \& Yamashita, 2018; Menke \& Paesani, 2019; Isik, 2018; Huensch, 2018; Han, 2018). Penelitian tersebut menggunakan pendekatan yang bervariasi dalam mengembangkan bahan ajar baik itu pendekatan integrated learning, multiliteracies framework, Task-Based Learning, dan beberapa pendekatan lainnya. Penggunaan pendekatan tersebut tentunya disesuaikan dengan kebutuhan dari pengajar dan pembelajar. Selain itu dalam mengembangkan bahan ajar tentunya disesuaikan dengan jenis keterampilan atau kemampuan yang akan diajarkan baik itu keterampilan menulis, berbicara, mendengarkan, membaca ataupun materi tata bahasa.

Kesalahan dalam memilih dan mengembangkan bahan ajar tentunya berdampak negatif pada pencapaian tujuan belajar dalam hal ini dapat berpengaruh pada hasil belajar, motivasi akademik pembelajar dan beberapa aspek lainnya. Maka dari itu bahan ajar sangat berperan pada kesuksesan proses pembelajaran (Montrieux dkk., 2015; Suparsa dkk., 2017; Cook, 2016; Solak, 2015). Dalam 
mengembangkan bahan ajar terdapat beberapa aspek lainnya yang sebaiknya diperhatikan selain aspek pendekatan yang digunakan baik itu aspek kemampuan awal siswa, kondisi lingkungan belajar, fasilitas belajar, dan kepribadian pengajar itu sendiri (Syamsuri dkk., 2017; Wulandari dkk., 2019; Ma, 2019).

Secara umum, penelitian ini fokus mengembangkan bahan ajar tata bahasa Jerman dengan menggunakan pendekatan linguistik terapan dalam hal ini adalah pendekatan analisis kesalahan berbahasa dan analisis kontrastif. Langkah awal dalam penelitian ini adalah melakukan analisis kebutuhan pembelajar yang nantinya akan digunakan sebagai dasar dalam penyusunan bahan ajar. Artikel penelitian ini fokus menggambarkan hasil dari analisis kebutuhan pembelajar tersebut.

\section{METODE PENELITIAN}

Jenis penelitian yang digunakan adalah kuantitatif. Pendekaatan ini digunakan untuk mengambarkan respon mahasiswa terkait analisis kebutuhan mereka terkait bahan ajar tata bahasa yang diinginkan secara deskripti kuantitatif. Beberapa respon mahasiswa tersebut yang berupa data kualitatif dan selanjutnya dikonversi menjadi data kuantitatif untuk dipersentasekan. Partisipan yang dilibatkan dalam penelitian ini adalah 30 mahasiswa pendidikan bahasa Jerman Universitas Negeri Makassar yang telah memprogramkan mata kuliah tata bahasa Jerman dasar. Teknik pengumpulan data yang digunakan yakni wawancara dan observasi. Teknik analisis data yakni deskriptif kualitatif dan statistik deskriptif.

\section{HASIL DAN PEMBAHASAN}

Berdasarkan data yang telah dikumpulkan, terdapat 4 aspek yang sebaiknya diperhatikan dalam sebuah buku ajar tata bahasa Jerman berdasarkan respon mahasiswa yang diperoleh dengan menggunakan wawancara, diantaranya adalah sebagai berikut:

\section{Komposisi setiap materi harus disesuaikan dengan analisis kebutuhan pembelajar}

Banyak buku ajar tata bahasa disusun tanpa memperhatikan komposisi dari setiap materi yang disajikan. Setiap materi disajikan dengan komposisi yang sama, padahal setiap materi mempunyai tingkat kesulitan yang berbeda, sehingga dalam menyajikan materi tersebut tentunya harus berdasarkan tingkat kesulitan materi tersebut. Materi yang mempunyai tingkat kesulitan yang tinggi sebaiknya mempunyai komposisi yang lebih banyak dibandingkan dengan materi yang mempunyai tingkat kesulitan yang rendah. Berikut adalah hasil respon mahasiswa terkait komposisi setiap materi yang harus disesuaikan dengan analisis kebutuhan pembelajar. 
Chart 1. Respon Mahasiswa terkait Komposisi Materi Buku Ajar

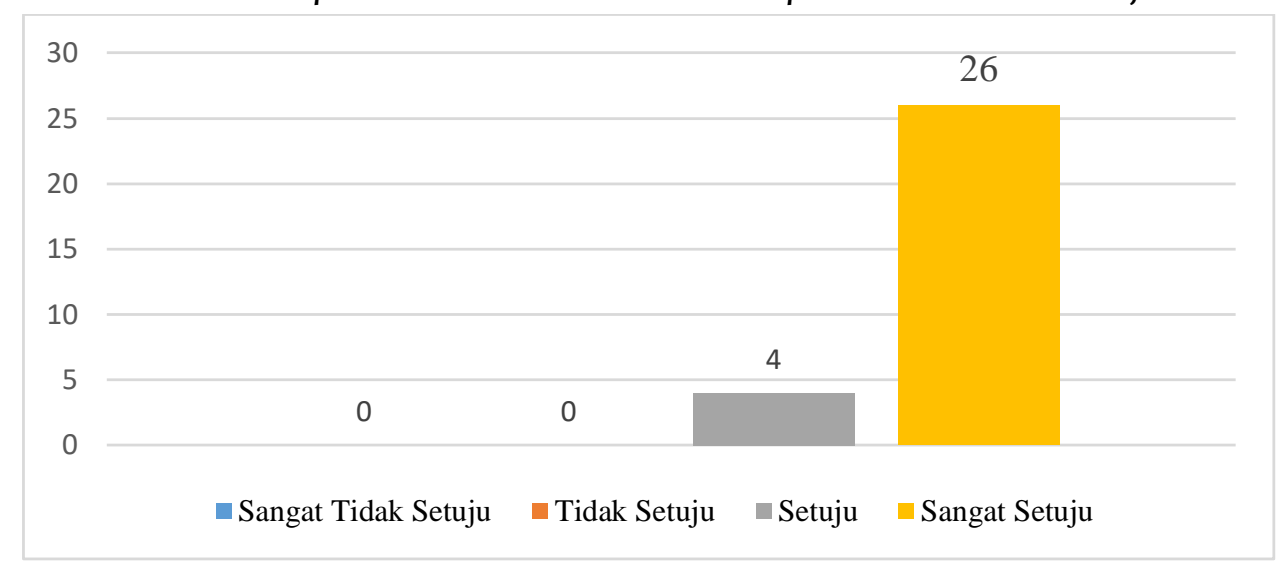

Hasil data kuantitatif menunjukkan bahwa semua responden setuju bahwa dalam komposisi setiap materi yang disajikan sebaiknya disesuaikan dengan analisis kebutuhan pembelajar. Untuk mengetahui tingkat kesulitan suatu materi, pendekatan yang dapat digunakan yakni analisis kesalahan berbahasa yang juga merupakan salah satu pendekatan dalam linguistik terapan.

\section{Penggunaan Analisis Kontrastif untuk Menjelaskan Tata Bahasa Jerman}

Salah satu cara yang dapat dilakukan untuk menjelaskan sebuah konsep tata bahasa adalah dengan memberikan contoh dengan menggunakan bahasa lain. Misalnya dalam menjelaskan kalimat pasiv dalam bahasa Jerman, pengajar dapat terlebih dahulu memberikan contoh kalimat pasiv bahasa Indonesia atau bahasa Inggris, agar mahasiswa dapat memahami terlebih dahulu apa yang dimaksud dengan kalimat pasiv. Berikut adalah hasil respon mahasiswa terkait penggunaan analisis kontrastif dalam menjelaskan tata bahasa Jerman:

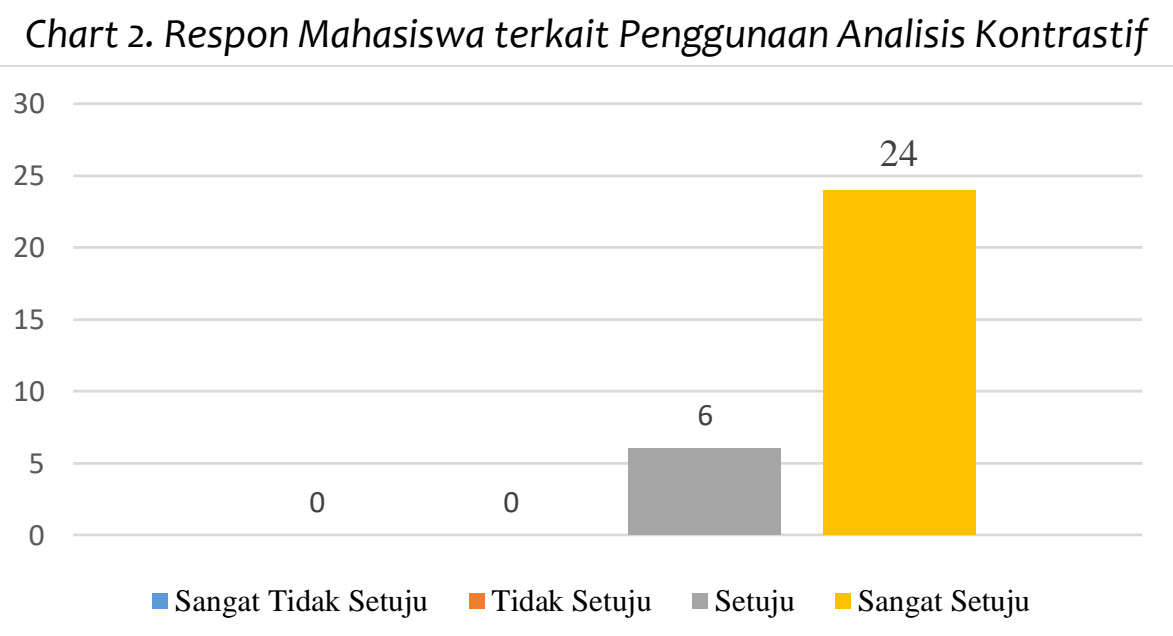

Hasil data kuantitatif menunjukkan bahwa semua responden dalam hal ini 24 mahasiswa pada kategori sangat setuju dan terdapat 6 mahasiswa pada kategori setuju terkait penggunaan analisis kontrastif dalam penyajian materi tata bahasa Jerman. Pendekatan analsisis kontrastif juga merupakan salah satu pendekatan 
dalam linguistik terapan yang bertujuan untuk mengetahui persamaan dan perbedaan dari dua bahasa atau lebih yang dibandingkan.

\section{Bentuk Soal Latihan yang Diberikan harus Bervariasi}

Untuk membantu mahasiswa dalam memahami materi yang telah dipelajari, maka dalam sebuah buku ajar terdapat beberapa soal latihan di setiap akhir materi. Namun terdapat beberapa buku ajar tidak menyajikan bentuk soal latihan yang bervariasi, buku tersebut hanya fokus pada satu atau dua bentuk soal latihan saja. Berikut adalah hasil respon mahasiswa terkait pemberian soal latihan yang bervariasi pada buku ajar tata bahasa Jerman:

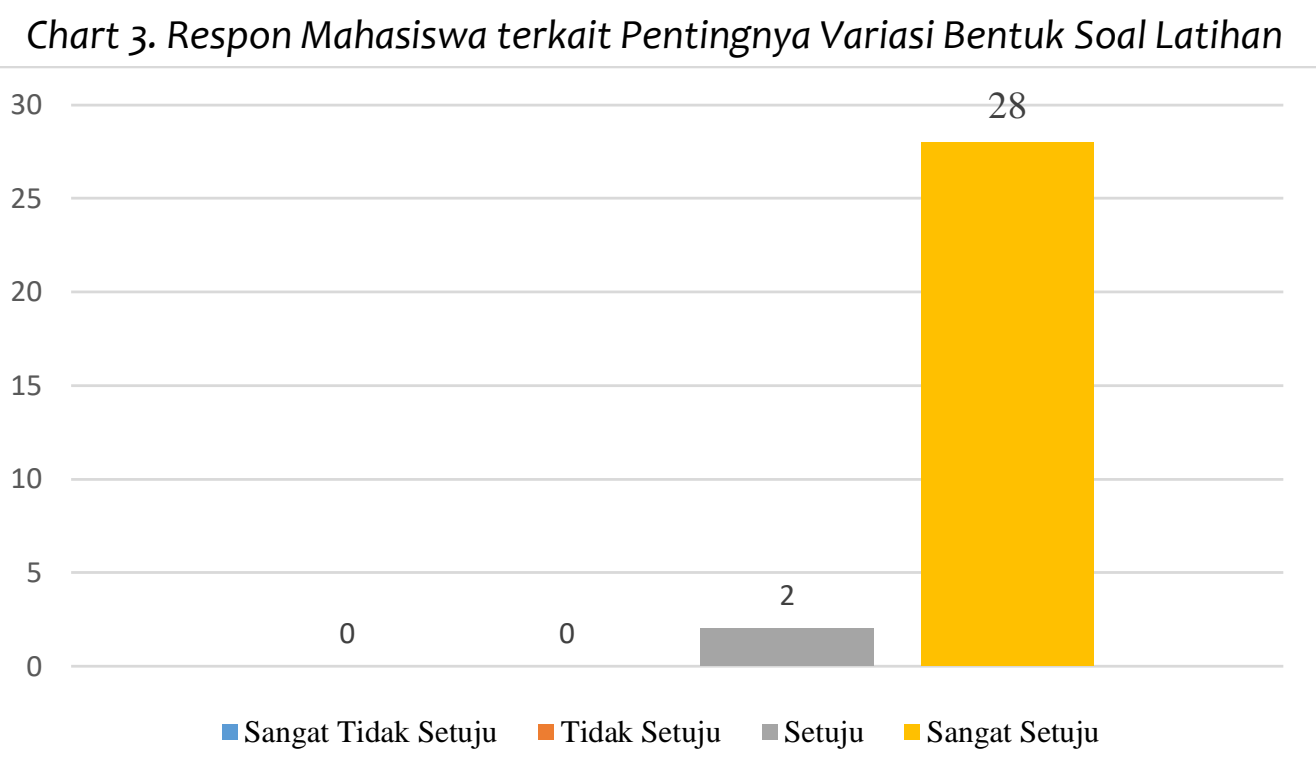

Hasil data kuantitatif menunjukkan bahwa semua responden dalam hal ini 28 mahasiswa pada kategori sangat setuju dan terdapat 2 mahasiswa pada kategori setuju terkait pemberian soal latihan yang bervariasi pada buku ajar tata bahasa Jerman. Terdapat beberapa jenis soal latihan yang ditawarkan mahasiswa berdasarkan hasil wawancara seperti tes benar salah, tes menyusun kalimat, tes membuat kalimat dengan menggunakan keywords yang tersedia, tes pilihan ganda, tes melengkapi kalimat, dan tes membenarkan kalimat salah.

\section{Menjelaskan Fenomena Tata Bahasa Jerman dengan Menggunakan Pendekatan Linguistik}

Salah satu kelemahan yang terdapat pada banyak buku ajar tata bahasa baik itu bahasa Inggris, Jerman atau bahasa lainnya adalah kurangnya penjelasan akan fenomena tata bahasa yang dipelajari dengan menggunakan pendekatan linguistik. Hal tersebut tentunya sangat penting karena pada hakikatnya ilmu linguistik tidak dapat dipisahkan dalam pembelajaran bahasa. Berikut adalah hasil respon mahasiswa terkait penggunaan pendekatan linguistik dalam penyajian materi pada buku ajar: 
Chart 4.

Respon Mahasiswa terkait Penggunaan Pendekatan Linguistik dalam Menjelaskan

Fenomena Tata Bahasa Jerman

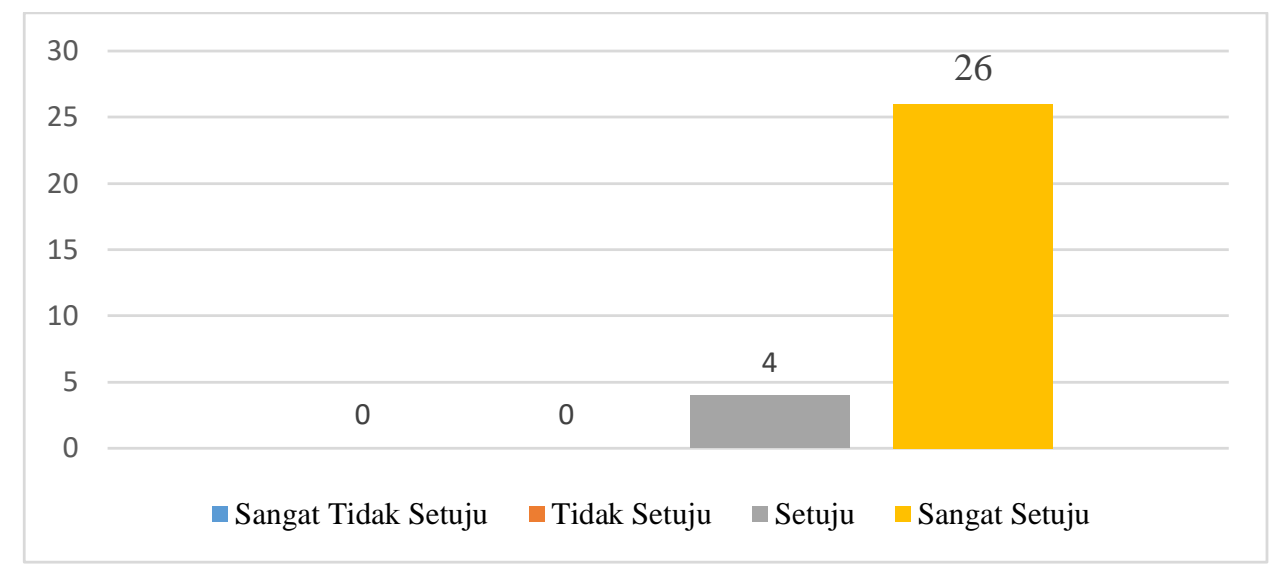

Hasil data kuantitatif menunjukkan bahwa semua responden memberikan respon positif terkait penggunaan pendekatan linguistik dalam penyajian materi pada buku ajar. Hasil wawancara dengan mahasiswa menunjukkan bahwa terkadang terdapat fenomena bahasa dalam bahasa Jerman yang tidak dapat dijelaskan oleh dosen karena dosen tersebut tidak mempunyai keahlian dalam ilmu linguistik baik itu seperti fenomena afiksasi, nominalisasi, deverbalisasi dan beberapa fenomena linguistik lainnya. Maka dari itu penting kiranya menyajikan materi dalam buku ajar tata bahasa dengan menggunakan pendekatan linguistik pada beberapa materi tertentu.

\section{KESIMPULAN}

Berdasarkan hasil analisis data dan pembahasan yang telah dijelaskan pada bagian sebelumnya maka dapat disimpulkan bahwa terdapat 4 aspek yang harus diperhatikan dalam menyusun buku ajar tata bahasa Jerhman. Keempat aspek tersebut diperoleh berdasarkan analisis kebutuhan pembelajar diantaranya adalah 1) Komposisi setiap materi harus disesuaikan dengan analisis kebutuhan pembelajar menggunakan analisis kesalahan berbahasa, 2) Penggunaan Analisis Kontrastif untuk Menjelaskan Tata Bahasa Jerman, 3) Bentuk Soal Latihan yang Diberikan harus Bervariasi, 4) Menjelaskan Fenomena Tata Bahasa Jerman dengan Menggunakan Pendekatan Linguistik.

\section{UCAPAN TERIMA KASIH}

Ucapan terima kasih kepada Ditjen Penguatan Riset dan Pengembangan Kementerian Riset, Teknologi, dan Pendidikan Tinggi Republik Indonesia yang telah mendanai penelitian ini melalui skema Penelitian Terapan Unggulan Perguruan Tinggi (PTUPT). Ucapan terima kasih juga disampaikan kepada Lembaga Penelitian dan 
Pengabdian kepada Masyarakat Universitas Negeri Makassar yang telah memfasilitasi pelaksanan penelitian ini.

\section{DAFTAR PUSTAKA}

Koda, K., \& Yamashita, J. (Eds.). (2018). Reading to Learn in a Foreign Language: An Integrated Approach to Foreign Language Instruction and Assessment. Routledge.

Menke, M. R., \& Paesani, K. (2019). Analysing foreign language instructional materials through the lens of the multiliteracies framework. Language, Culture and Curriculum, 32(1), 34-49.

Isik, A. (2018). Do English Teaching Materials Foster Foreign Language Education Affectively?. Journal of Education and Learning, 7(1), 272-280.

Huensch, A. (2018). Pronunciation in foreign language classrooms: Instructors' training, classroom practices, and beliefs. Language Teaching Research, 1362168818767182.

Han, Z. (2018). Task-Based Learning in Task-Based Teaching: Training Teachers of Chinese as a Foreign Language. Annual Review of Applied Linguistics, 38, 162-186.

Montrieux, H., Vanderlinde, R., Schellens, T., \& De Marez, L. (2015). Teaching and learning with mobile technology: A qualitative explorative study about the introduction of tablet devices in secondary education. PloS one, 10(12), e0144008.

Suparsa, I. N., Mantra, I. B. N., \& Widiastuti, I. A. M. S. (2017). Developing learning methods of Indonesian as a foreign language. International journal of social sciences and humanities, 1(2), 51-57.

Cook, V. (2016). Second language learning and language teaching. Routledge.

Solak, E., \& Cakir, R. (2015). Exploring the Effect of Materials Designed with Augmented Reality on Language Learners' Vocabulary Learning. Journal of Educators Online, 12(2), 50-72.

Syamsuri, B. S., Anwar, S., \& Sumarna, O. (2017, September). Development of Teaching Material Oxidation-Reduction Reactions through Four Steps Teaching Material Development (4S TMD). In Journal of Physics: Conference Series (Vol. 895, No. 1, p. 012111). IOP Publishing.

Wulandari, D., Rosiana, A., \& Abidin, H. Z. (2019, February). The Development of Science Teaching Materials Based On Practicum in Applying Motion Energy Concept Topic. In International Conference Primary Education Research Pivotal Literature and Research UNNES 2018 (IC PEOPLE UNNES 2018). Atlantis Press.

Ma, N. (2019, April). Discussion on Cultivation of Critical Thinking of Foreign Language Majors from the Perspective of Teaching Practice. In 3rd International Conference on Culture, Education and Economic Development of Modern Society (ICCESE 2019). Atlantis Press. 